Comparison of the variability of the onset and recovery from neuromuscular blockade with cisatracurium versus rocuronium in elderly patients under total intravenous anesthesia

Feng Xiaobo, Ke Jianjuan and Wang Yanlin

The Brazilian Journal of Medical and Biological Research is partially financed by
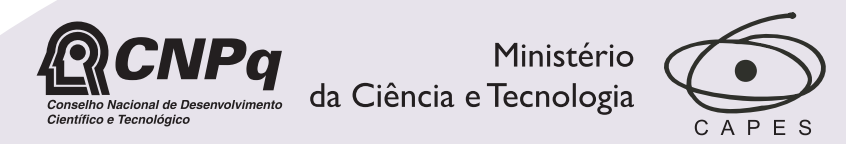

Ministério da Educação
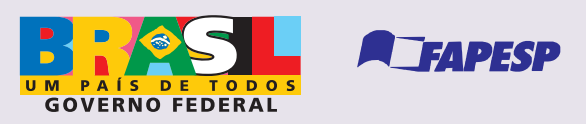

Institutional Sponsors
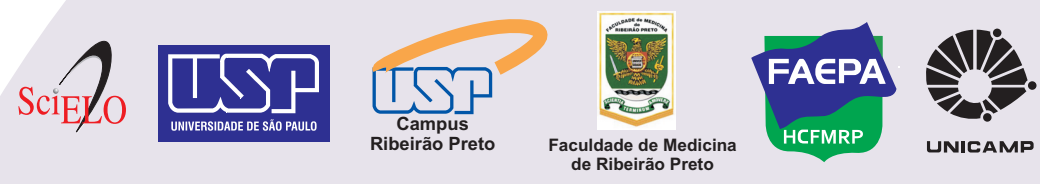

Ф SHIMADZU UNICAMP

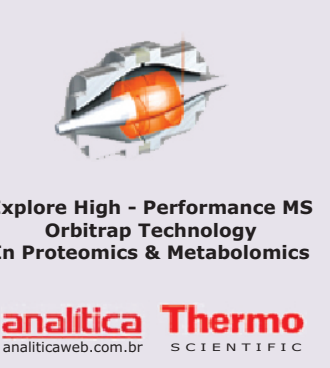

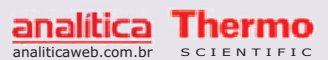




\title{
Comparison of the variability of the onset and recovery from neuromuscular blockade with cisatracurium versus rocuronium in elderly patients under total intravenous anesthesia
}

Feng Xiaobo, Ke Jianjuan and Wang Yanlin

Department of Anesthesiology, Zhongnan Hospital, Wuhan University, Wuhan, China

\begin{abstract}
This study was designed to compare the variability of the onset and offset of the effect of two neuromuscular blocking drugs with different elimination pathways in adult and elderly patients during total intravenous anesthesia (TIVA). After Ethics Committee approval and patients' informed consent, the drugs were compared in 40 adult and 40 elderly patients scheduled for elective surgery under TIVA with tracheal intubation who were randomized to receive a single bolus dose of $0.15 \mathrm{mg} / \mathrm{kg}$ cisatracurium or $0.9 \mathrm{mg} / \mathrm{kg}$ rocuronium. The time of onset of maximum depression, duration of action, and recovery index time were measured and recorded for each patient and variability is reported as means \pm standard deviation. Time of onset was significantly shorter for rocuronium than cisatracurium for the adult and elderly groups $(P=0.000)$, but the variability of cisatracurium was significantly greater compared with rocuronium for the same age groups (93.25 vs $37.01 \mathrm{~s}$ in the adult group and $64.56 \mathrm{vs} 33.75 \mathrm{~s}$ in the elderly group; $P=0.000$ ). The duration of the effect in the elderly group receiving rocuronium was significantly longer than in the elderly group receiving cisatracurium, and the variability of the duration was significantly greater in the rocuronium group than in the cisatracurium group. Mean time of recovery was significantly longer for the elderly group receiving rocuronium than for the elderly group receiving cisatracurium $(P=0.022)$, and variability was also greater $(P=0.002)$. Both drugs favored good intubating conditions. In conclusion, cisatracurium showed less variability in these parameters than rocuronium, especially in the elderly, a fact that may be of particular clinical interest.
\end{abstract}

Key words: Neuromuscular relaxant; Rocuronium; Cisatracurium; Variability; Elderly

\section{Introduction}

Adequate control of the duration and quality of neuromuscular blockade (NBD) during surgery is essential for safe and successful surgery, but incomplete recovery of neuromuscular function can endanger patients, decrease the sensitivity to hypoxia, augment the risk of lung complications, cause aspiration, upper airway obstruction, visual trouble, and dysphagia $(1,2)$, and also slow the throughput of patients in the operation room by increasing the time of resuscitation. Thus, the proper use of NBD neuromuscular blockers is important (3).

Two strategies to avoid postoperative residual paralysis exist at present: the first is the use of cholinesterase inhibitors, which, however, are applied in only about $25 \%$ of cases, suggesting that this approach is not the first line strategy throughout the world (4); the second is to avoid overdosing patients with NBD via careful monitoring and thorough titration of the muscle relaxant (5).

Variability shows how spread out or closely clustered a set of data is. It is expressed as variance or standard deviation in statistics. In our study, the variability of NBD showed the stability of the onset and offset time in the population, which may help anesthesiologists predict the complete recovery of neuromuscular function, with the postoperative safety of patients being insured considerably and the throughput of patients in the operation room being expedited.

Rocuronium is a steroid-based, intermediate acting relatively low-potency NBD, primarily eliminated via the liver. Its main advantage is the rapid onset of neuromuscular block. In contrast to the steroid-based NBD, the benzylisoquinolinium

Correspondence: Wang Yanlin, Department of Anesthesiology, Zhongnan Hospital, University of Wuhan, Wuhan 430071,

Hubei Province, China. E-mail: kejianjuan@yahoo.com.cn

Received August 10, 2011. Accepted April 24, 2012. Available online May 18, 2012. Published July 2, 2012. 
cisatracurium is broken down via Hofmann elimination in an organ-independent fashion (6-8). We wondered if the duration of action and variability are greater for rocuronium than for cisatracurium. Since the variability of the onset and duration of the effect of the two drugs has not been compared in the elderly population under total intravenous anesthesia (TIVA), the aim of this study was to compare the pharmacodynamic parameters following the administration of a single dose of $0.15 \mathrm{mg} /$ $\mathrm{kg}$ cisatracurium and $0.9 \mathrm{mg} / \mathrm{kg}$ rocuronium to elderly patients, with special attention paid to the variability of these parameters.

\section{Material and Methods}

The study was approved by the local Ethics Committee (Zhongnan Hospital, Wuhan University) and was conducted on 80 adult patients: 40 adult (18-64 years) and 40 elderly ( $\geq 65$ years) patients, American Society of Anesthesiologists (ASA) physical status I-II scheduled for elective general surgery under TIVA with tracheal intubation, muscle relaxation and mechanical ventilation. All patients gave written informed consent to participate in the study. Exclusion criteria were ASA physical status more than III, age under 18 and over 75 years, obesity [body mass index (BMI) over $30 \mathrm{~kg} / \mathrm{m}^{2}$ ], patients receiving medication known to interfere with NBDs (anticonvulsants, aminoglycosides, or polypeptide antibiotics), patients with anticipated difficult intubation (Mallampati (9) score III and more), and those with diseases affecting neuromuscular transmission (myopathies).

A pre-anesthetic questionnaire was used to collect patients' demographic data - gender, age, weight, height, ASA classification, and derived parameters (BMI, body surface area) were computed. Patients were randomly assigned to 4 groups of 20 each: in the cisatracurium groups, adult and elderly patients received $0.15 \mathrm{mg} / \mathrm{kg}$ cisatracurium; in the rocuronium groups, adult and elderly patients received $0.9 \mathrm{mg} / \mathrm{kg}$ rocuronium. A method of computer-generated random numbers with blockwise randomization was used to obtain balanced sample sizes in all groups.

\section{Anesthesia}

Upon patient arrival in the operation room, the electrocardiogram, hemoglobin oxygen saturation and noninvasive arterial pressure were monitored.

TIVA was induced and maintained with the infusion device and adjusted according to clinical response during anesthesia. Anesthetic induction was obtained with $0.1 \mathrm{mg} /$ $\mathrm{kg}$ midazolam, $1.5 \mathrm{mg} / \mathrm{kg}$ propofol and 3-4 $\mu \mathrm{g} / \mathrm{kg}$ fentanyl; $0.9 \mathrm{mg} / \mathrm{kg}$ rocuronium or $0.15 \mathrm{mg} / \mathrm{kg}$ cisatracurium was then injected over $5 \mathrm{~s}$ into a preflushed rapidly running iv line. Anesthesia was maintained with a continuous infusion of $4-8 \mathrm{mg} \cdot \mathrm{g}^{-1} \cdot \mathrm{h}^{-1}$ propofol and $0.05-0.5 \mu \mathrm{g} \cdot \mathrm{kg}^{-1} \cdot \mathrm{min}^{-1}$ remifentanil.

\section{Neuromuscular block and monitoring}

TOF-Watch SX (Ireland) is the most advanced device in the TOF-Watch range of neuromuscular transmission monitors, fully compliant with Good Clinical Practice guidelines. Electrodes for ulnar nerve stimulation were placed at the wrist on the radial side of the flexor carpi ulnaris muscle and 2-3 cm proximal to the distal electrode. The acceleration transducer used to monitor neuromuscular function was placed on the volar side of the distal phalanx of the thumb with no preload to the thumb. The arm was cushioned and supported to allow unrestricted movement of the thumb. Every $12 \mathrm{~s}$, neuromuscular transmission was monitored as the evoked response of the adductor pollicis muscle to a supramaximal train of four (TOF) electrical stimulation (0.2$\mathrm{ms}$ square wave at $50 \mathrm{~mA}$ at a frequency of $1 \mathrm{HZ}$ ). When the response after TOF was zero, direct laryngoscopy was initiated followed by tracheal intubation. The conditions for intubation were recorded according to the scales published by Claudius and Viby-Mogensen (10). Anesthesia was maintained with a continuous infusion of $4-8 \mathrm{mg} \cdot \mathrm{kg}^{-1} \cdot \mathrm{h}^{-1}$ propofol and $0.05-0.5 \mu \mathrm{g} \cdot \mathrm{kg}^{-1} \cdot \mathrm{min}^{-1}$ remifentanil. When the response to TOF was one, the maintenance doses of NBD were administered, $0.025 \mathrm{mg} / \mathrm{kg}$ cisatracurium and $0.15 \mathrm{mg} /$ $\mathrm{kg}$ rocuronium. Anesthesia was maintained during controlled ventilation (30-35 mmHg EtCO 2 ). Fluids and pressors were given as needed to maintain heart rate and mean arterial pressure within $25 \%$ of awake baseline. For each patient, the onset time of maximum depression (time between completed injection of the initial dose of neuromuscular blocking drugs to TOF zero response), duration of action (based on the time from the completion of injection of the initial dose to a TOF response of one), and recovery index (defined as the mean \pm SD time interval in minutes from TOF 25 to $75 \%$ after the last bolus dose) were measured and recorded. Variability was reported as the standard deviation around the mean.

\section{Statistical analysis}

The mean \pm SD values were calculated for patients' demographics in all groups, and analysis of variance (ANOVA) was performed to test for statistical differences. Categorical data (i.e., gender, ASA status, BMI, incidence of adverse events) were compared using the chi-square test. Mean values of the continuous data (i.e., onset time, duration of action and recovery index) were compared using Tamhane's T2. The comparison of the variability in onset time, duration of action and recovery index was performed using the F-test. $\mathrm{P} \leq 0.05$ represents a statistically significant difference.

\section{Results}

Eighty patients were enrolled in the study. The characteristics of the study groups are presented in Table 1; no significant differences existed among these groups. 
Time of onset of the effect of cisatracurium was 249.30 $\pm 93.25 \mathrm{~s}$ for the adult group and $261.00 \pm 64.56 \mathrm{~s}$ for the elderly group; for rocuronium, time was $115.90 \pm 37.01$ and $104.25 \pm 33.75 \mathrm{~s}$, respectively. The time of onset and the variability were comparable between the elderly and adult patients receiving cisatracurium or rocuronium $(P=0.998$, $P=0.552$, respectively); the mean time was significantly shorter for rocuronium compared to cisatracurium in both the adult and elderly groups $(P=0.000)$. However, the result of variability was inverse, with greater variability in onset being observed for cisatracurium compared to rocuronium in the same age groups $(P=0.000)$.

The duration of neuromuscular block was $49.50 \pm 9.15$ min (adult group) and $50.45 \pm 4.66 \mathrm{~min}$ (elderly group) for cisatracurium, and $48.30 \pm 13.97 \mathrm{~min}$ (adult group) and $70.75 \pm 27.31 \mathrm{~min}$ (elderly group) for rocuronium. The duration was significantly longer in the elderly group than in the adult group receiving rocuronium $(P=0.017)$, but comparable between the adult and elderly groups receiving cisatracurium $(P=0.999)$. The duration in the elderly group receiving rocuronium was significantly longer than that in the elderly group receiving cisatracurium. In addition, the variability of the duration in the elderly group receiving rocuronium was significantly greater than that in the same age group receiving cisatracurium.

The recovery index was $15.30 \pm 2.55 \mathrm{~min}$ (adult group) and $15.50 \pm 2.28 \mathrm{~min}$ (elderly group) for cisatracurium, and $17.10 \pm 7.04 \mathrm{~min}$ (adult group) and $22.40 \pm 7.16 \mathrm{~min}$ (elderly group) for rocuronium. The mean time of recovery index was significantly longer and the variability much greater for rocuronium than cisatracurium in the elderly group.

The variability around the mean value of these parameters of each study drug is illustrated in Figure 1 for the respective age subgroups.

\section{Discussion}

Postoperative residual neuromuscular blockade is an important event that may contribute to postoperative pulmonary complications (11). Thus, the ideal muscle relaxants should provide a more predictable recovery from their neuromuscular block. This characteristic is particularly relevant when treating elderly patients. The present study demonstrated a significantly smaller variability in the duration and recovery time of cisatracurium compared to rocuronium in adult and elderly subjects.

In the present study, the onset time of the effect of equipotent doses $(0.9$ and $0.15 \mathrm{mg} / \mathrm{kg}$ ) was significantly shorter with rocuronium than with cisatracurium. Rocuronium is a relatively low-potency, intermediate acting NBD, which is commonly used during anesthesia. It is taken up principally by the liver and excreted in the bile (12). The

Table 1. Demographic data of the patients studied.

\begin{tabular}{lcccc}
\hline & ROC adult & ROC elderly & CIS adult & CIS elderly \\
\hline Age (years) & $38.15 \pm 12.08$ & $72.00 \pm 3.83$ & $41.70 \pm 13.13$ & $71.40 \pm 5.10$ \\
Men/women & $9 / 11$ & $12 / 8$ & $10 / 10$ & $11 / 9$ \\
BMI $\left(\mathrm{kg} / \mathrm{m}^{2}\right)$ & $20.44 \pm 1.96$ & $21.33 \pm 1.86$ & $20.07 \pm 1.70$ & $21.09 \pm 1.59$ \\
\hline
\end{tabular}

Data are reported as means \pm SD or number for 20 patients/group. ROC $=$ rocuronium; $\mathrm{CIS}=$ cisatracurium; $\mathrm{BMI}=$ body mass index.
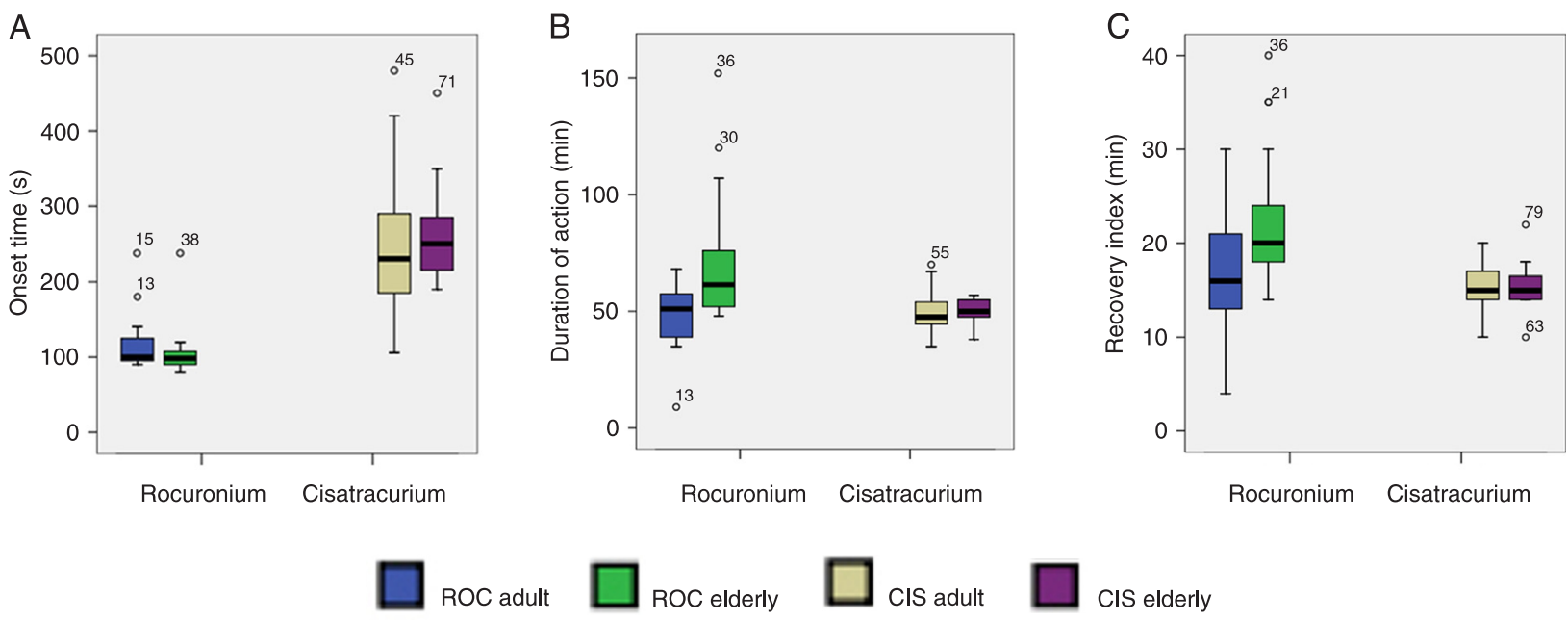

Figure 1. Comparison of the effect of rocuronium (ROC) and cisatracurium (CIS) on onset time $(A)$, duration of action $(B)$ and recovery index $(C)$ for 20 patients (ROC/CIS adults and ROC/CIS elderly) in each group. Data are reported as plots of quartiles (boxes), median (line within box), 10th and 90th percentiles (error bars), and outliers (open circles). The maintenance doses were $0.025 \mathrm{mg} / \mathrm{kg} \mathrm{CIS} \mathrm{and}$ $0.15 \mathrm{mg} / \mathrm{kg}$ ROC. 
main advantage of rocuronium is the rapid onset of neuromuscular blockade, which has led to its use in conditions where succinylcholine is relatively or absolutely contraindicated. An inverse relationship between molar potency and onset time of neuromuscular blockade has been shown for nondepolarizing NBDs of both long and intermediate duration. A rapid onset of action is characteristic of drugs with low potency, so the onset time of rocuronium is significantly shorter compared with cisatracurium. Another report suggested that rocuronium possesses an unusually high affinity for presynaptic sites compared to other nondepolarizing NBDs. Perhaps this is another reason for the rapid onset of the effect of rocuronium. In the elderly population $(13,14)$, when somebody at risk of aspiration (unconsciousness, intestinal obstruction, etc.) needs rapid intubation, rocuronium is a very good alternative for a rapid onset of neuromuscular blockade.

However, the duration and recovery index were significantly longer in the elderly group compared with the adult group receiving rocuronium. Furthermore, the corresponding variability in the elderly rocuronium group was significantly greater compared to the adult group. Age-related changes occur in the neuromuscular junction, but Matteo et al. (15) found that there is no alteration of the sensitivity of the acetylcholine receptor with increasing age. However, with increasing age the change of function of vital organs may influence the pharmacokinetics of neuromuscular blocking drugs. Although the patients we studied had no abnormal renal and liver function, subclinical age-related changes may have existed. For example, a reduction in cardiac output, decreased hepatic and renal blood flow, smaller liver mass, and lower glomerular filtration rate may decrease the rate of elimination of neuromuscular blocking agents $(16,17)$. Thus, the differences in distribution and elimination of NBDs via organ-dependent elimination in the elderly have been suggested to be likely explanations for the prolonged offset time and the corresponding variability (18).

Whereas the duration of action and spontaneous recovery increased with rocuronium in elderly patients, these parameters were comparable for adult and elderly patients treated with cisatracurium. In elderly patients, the variability

\section{References}

1. Igarashi A, Amagasa S, Horikawa H, Shirahata M. Vecuronium directly inhibits hypoxic neurotransmission of the rat carotid body. Anesth Analg 2002; 94: 117-122.

2. Baillard C, Gehan G, Reboul-Marty J, Larmignat P, Samama $\mathrm{CM}$, Cupa M. Residual curarization in the recovery room after vecuronium. Br J Anaesth 2000; 84: 394-395.

3. Maybauer DM, Geldner G, Blobner M, Puhringer F, Hofmockel $\mathrm{R}, \operatorname{Rex} \mathrm{C}$, et al. Incidence and duration of residual paralysis at the end of surgery after multiple administrations of cisatracurium and rocuronium. Anaesthesia 2007; 62: 12-17.

4. Cammu G, De Witte J, De Veylder J, Byttebier G, Vandeput in the duration of action and spontaneous recovery after the last drug dose was significantly greater for rocuronium than for cisatracurium. This result may correlate with the elimination of the two drugs: the organ-dependent elimination of rocuronium and the organ-independent elimination of cisatracurium.

It has been well documented that the clearance and plasma half-life of rocuronium are prolonged with normal aging. This has not been the case with cisatracurium. Cisatracurium is one of the stereoisomers that make up atracurium, and Hofmann elimination may have a greater role in the elimination of cisatracurium than in the elimination of atracurium (7). Thus, for the elderly patients cisatracurium was a good choice, with similar and constant duration and recovery index between the adult and the elderly populations. The anesthesiologist could make sure of the postoperative safety of patients and the rapidity of throughput of patients in the operation room because of its more predictable behavior.

The onset of the action of cisatracurium was slower than that of rocuronium. This difference has been explained by the slower biophase equilibration, resulting in a delayed and reduced peak concentration of cisatracurium at the effector site, but in our study there was no significant difference in onset between adult and elderly patients receiving cisatracurium. Sorooshian et al. (19) suggested that the onset of the effect of cisatracurium was marginally rapid in young patients compared to elderly patients, and the primary factor was a reduced rate of biophase equilibration in the elderly (being reduced to $0.060 / \mathrm{min}$ in the elderly as compared to $0.071 / \mathrm{min}$ in the young).

We observed a comparable duration of action of and recovery from neuromuscular block in adult and elderly patients receiving cisatracurium in contrast to a prolonged offset in the elderly after rocuronium. Furthermore, cisatracurium showed less variability in these parameters than rocuronium, especially in the elderly where this may be of particular clinical interest. However, the variability of the onset time for the two age groups was greater for cisatracurium than for rocuronium. This point still needs further research.
$D$, Foubert L, et al. Postoperative residual paralysis in outpatients versus inpatients. Anesth Analg 2006; 102: 426-429.

5. Fuchs-Buder T, Eikermann M. [Residual neuromuscular blockades. Clinical consequences, frequency and avoidance strategies]. Anaesthesist 2006; 55: 7-16.

6. Kisor DF, Schmith VD. Clinical pharmacokinetics of cisatracurium besilate. Clin Pharmacokinet 1999; 36: 27-40.

7. Smith CE, van Miert MM, Parker CJ, Hunter JM. A comparison of the infusion pharmacokinetics and pharmacodynamics of cisatracurium, the 1R-cis 1'R-cis isomer of atracurium, with atracurium besylate in healthy patients. Anaesthesia 
1997; 52: 833-841.

8. Atherton DP, Hunter JM. Clinical pharmacokinetics of the newer neuromuscular blocking drugs. Clin Pharmacokinet 1999; 36: 169-189.

9. Mallampati SR, Gatt SP, Gugino LD, Desai SP, Waraksa B, Freiberger D, et al. A clinical sign to predict difficult tracheal intubation: a prospective study. Can Anaesth Soc J 1985; 32: 429-434.

10. Claudius C, Viby-Mogensen J. Acceleromyography for use in scientific and clinical practice: a systematic review of the evidence. Anesthesiology 2008; 108: 1117-1140.

11. Martinez EA. Neuromuscular blocking agents. Vet Clin North Am Equine Pract 2002; 18: 181-188.

12. Bowman WC. Neuromuscular block. Br J Pharmacol 2006; 147 (Suppl 1): S277-S286.

13. Lighthall GK, Jamieson MA, Katolik J, Brock-Utne JG. A comparison of the onset and clinical duration of high doses of cisatracurium and rocuronium. J Clin Anesth 1999; 11: 220-225.

14. England AJ, Panikkar K, Redai I, Haxby E, Gopinath S, Feldman SA. Is rocuronium an exception to the relation between onset and offset? A comparison with pipecuronium. Eur $J$
Anaesthesiol 1996; 13: 385-388.

15. Matteo RS, Ornstein E, Schwartz AE, Ostapkovich N, Stone JG. Pharmacokinetics and pharmacodynamics of rocuronium Org 9426 in elderly surgical patients. Anesth Analg 1993; 77: 1193-1197.

16. Arain SR, Kern S, Ficke DJ, Ebert TJ. Variability of duration of action of neuromuscular-blocking drugs in elderly patients. Acta Anaesthesiol Scand 2005; 49: 312-315.

17. Puhringer FK, Heier T, Dodgson M, Erkola O, Goonetilleke P, Hofmockel R, et al. Double-blind comparison of the variability in spontaneous recovery of cisatracurium- and vecuroniuminduced neuromuscular block in adult and elderly patients. Acta Anaesthesiol Scand 2002; 46: 364-371.

18. de Almeida MC, Latorre F, Gervais HW, Kleeman PP. [The effects of age on onset and recovery from atracurium, rocuronium and vecuronium blockade]. Anaesthesist 1996; 45: 903-906.

19. Sorooshian SS, Stafford MA, Eastwood NB, Boyd AH, Hull CJ, Wright PM. Pharmacokinetics and pharmacodynamics of cisatracurium in young and elderly adult patients. Anesthesiology 1996; 84: 1083-1091. 